\title{
MEYRIAT, FOSKETT E A COMPETÊNCIA EM INFORMAÇÃO
}

\begin{abstract}
Resumo: O trabalho efetua uma revisão das contribuições teóricas de Jean Meyriat, que concebe e enfatiza a atuação do usuário da informação no sistema técnico social da informação, concebendo o documento numa perspectiva dialética, interativa e dinâmica, e de Foskett sobre os sistemas formais de comunicação do conhecimento, nas quais o usuário tem papel preponderante. A formação deste usuário proposto por Meyriat exige uma perspectiva pedagógica também interacionista quese associaao conceito de competência em informação,entendida de modo geral, como a capacidade de reconhecer quando a informação é necessária, ter a capacidade de localizar, avaliar e utilizar eficazmente a informação e preservá-la para reutilização futura, conceito proposto pela American Library Association e pela UNESCO, através de uma abordagem epistemológica e pedagógica de caráter interacionista e crítica. A partir desta triangulação aborda criticamente a perspectiva pedagógica do aprender a aprender naquilo que ela tem de redução do sujeito usuário da informação ao individualismo competitivo e hierarquizante, o que favorece o encrudescimento da exclusão que contraria os próprios princípios norteadores da Competência em Informação e dos conceitos de Documento e Documentação. Propõe a concepção pedagógica numa perspectiva emancipatória, fazendo avançar o ensino e a aprendizagem na direção democrática de um usuário solidário que ativa o documento utilizando suas capacidades cognitivas plenamente.
\end{abstract}

Palavras-Chave: Documento, Documentação, Competência em Informação.

\author{
Joselito Manoel de Jesus \\ Doutorando em Ciência da \\ Informação no Instituto de Ciência \\ de Informação da Universidade \\ Federal da Bahia. Professor da \\ Universidade do Estado da Bahia, \\ Departamento de Ciências \\ Humanas, DCH IV, Jacobina. E- \\ mail: jiesus@uneb.br
}

Fernanda Maria Melo Alves Professora Convidada do PPGCI da Universidade Federal da Bahia. Realizou estágio pós-doutoral nas UniversidadesFederal da Bahia, Estadual de Londrina e no Instituto de Estudos e Pesquisas (INEP) da Guiné Bissau. Tem doutoramento em Documentación: Archivos y Bibliotecas em Entorno Digital pela Universidade Carlos III de Madrid, Espanha. E-mail: fmeloa2@hotmail.com

\section{MEYRIAT, FOSKET AND THE INFORMATION LITERACY}

\begin{abstract}
The work reviews the theoretical contributions of Jean Meyriat, who conceives and emphasizes the performance of the user of information in the technical social system of information, designing the document in a dialectic, interactive and dynamic perspective, and Foskett about formal systems of communication of knowledge, in which the user has a preponderant role. The training of this user proposed by Meyriat requires a pedagogical perspective also interactionist that associates to the concept of competence in information, generally understood, as the ability to recognize when information is necessary, to have the ability to locate, evaluate and effectively use the information and preserve it for future re-use, a concept proposed by the American Library Association and UNESCO, through an epistemological and pedagogical approach of an interactive and critical character. From this triangulation critically addresses the pedagogical perspective of learning to learn what it has from reducing the user of information to competitive and hierarchical individualism, This favors the encrudement of exclusion that is contrary to the very principles guiding the Information Literacy and the concepts of Document and Documentation. It proposes pedagogical conception from an emancipatory perspective, advancing teaching and learning in the democratic direction of a supportive user that activates the document using its cognitive abilities fully.
\end{abstract}

Keywords: Document, Documentation, Information literacy. 


\section{MEYRIAT, FOSKETT Y LA ALFABETIZZACIÓN INFORMACIONAL}

Resumen: El trabajo realiza una revisión de las contribuciones teóricas de Jean Meyriat, que concibe y enfatiza la actuación del usuario de la información en el sistema técnico social de la información, concibiendo el documento en una perspectiva dialéctica, interactiva y dinámica, y Foskett sobre los sistemas formales de comunicación del conocimiento, en los cuales el usuario tiene papel preponderante. La formación de este usuario propuesto por Meyriat exige una perspectiva pedagógica también interaccionista que asocia el concepto de competencia en información, entendida de modo general, como la capacidad de reconocer cuando la información es necesaria, tener la capacidad de localizar, evaluar y utilizar eficazmente la información y preservarla para su reutilización futura, concepto propuesto por la American Library Association y la UNESCO, a través de un enfoque epistemológico y pedagógico de carácter interaccionista y crítico. A partir de esta triangulación aborda críticamente la perspectiva pedagógica del aprender a aprender en aquello que tiene de reducción del sujeto usuario de la información al individualismo competitivo y jerarquizante, lo que favorece el recrudecimiento de la exclusión que va en contra de los propios principios rectores de la competencia en información y los conceptos de documento y documentación. Propone la concepción pedagógica en una perspectiva emancipadora, haciendo avanzar la enseñanza y el aprendizaje en la dirección democrática de un usuario solidario, que activa el documento, utilizando plenamente sus capacidades cognitivas.

Palabras clave: Documento, Documentación, Alfabetización Informacional.

\section{INTRODUÇÃO}

"O usuário faz o documento". Esta afirmação de Jean Meyriat (2016) representa uma síntese relevante para entender sua reflexão sistemática sobre o documento, a documentação e a documentologia, definições que estão interligadas e que são necessárias para o entendimento das implicações da atividade documentária no campo da Ciência da Informação e em outros campos do conhecimento.

Ao "fazer o documento", o usuário se torna o ator primordial de toda cadeia documentária, o que nos conduz a perguntar sobre a formação desse usuário na competência em informação, que requeira o aprendizado ao longo da vida, na perspectiva pedagógica do aprender a aprender, mas que coloque os processos interativos e solidários acima dos individualismos reducionistas, individualismos estes que promovem práticas sociais hierarquizantes e discriminatórias.

A essência da atividade documentária está naquele que busca a informação, o usuário, embora se reconheça que uma "competência em documentação" é necessária ao documentalista 
[..] que exerce a atividade documentária, e que pode ser ele mesmo uma pessoa, um grupo ou uma instituição. Na prática, existem todos os casos possíveis entre, de um lado, o próprio pesquisador buscando a informação que precisa e, de outro lado, o organismo ou a central documentária explorando uma massa considerável de documentos a fim de extrair as informações prontas para serem dadas em resposta àqueles que se dirigem a ela (MEYRIAT, 2016, p. 246-247).

Percebemos que a competência em informação, do ponto de vista do usuário, é uma condição para a dinâmica e o desenvolvimento da atividade da documentação, entendendo esta última como "técnica, ou o conjunto de técnicas, utilizadas para coletar, classificar, explorar... documentos (MEYRIAT, 2016, p.245).

A atividade documentária enquanto levantamento de um conjunto de documentos feitos pelo pesquisador ou instituição afim, circunscrita à competência em informação, é entendida de modo geral, como a capacidade de reconhecer quando a informação é necessária, ter a capacidade de localizar, avaliar e utilizar eficazmente a informação e preservá-la para reutilização futura (ALA, 1989). Portanto, como não existe informação sem o seu suporte, e como a significação da informação é inseparável do suporte que a contêm, a competência em informação e a documentação encontram-se entrelaçadas indissoluvelmente, o que nos abre um vasto campo de reflexão sobre a pedagogia que subjaz a estas relações.

\section{DOCUMENTO, DOCUMENTAÇÃO E POLÍtiCA PARA A FORMAÇÃo DO USUÁRIO}

Para Meyriat, o documento "[...] pode ser definido como um objeto que suporta a informação, que serve para comunicar e que é durável (a comunicação pode, assim, ser repetida)" e, todo objeto pode se tornar documento, a partir do sujeito que lhe saiba interrogar (MERIAT, 2016, p.241).

Esse "saber interrogar" não nasce dado, numa perspectiva apriorista de aprendizagem, nem ocorre por transmissão pura e simples de uma pessoa para outra, como numa perspectiva epistemológica empirista. Meyriat nos oferece uma perspectiva de documento, que nos obriga a transitarmos de uma concepção passiva para sua constituição ativa, interativa e dialética, na qual os usuários, os documentos, as técnicas, enfim, todo o sistema técnico-social da documentação está em permanente transformação. Segundo ele 
[...] pode-se dizer que a capacidade informativa de um documento jamais se esgota pelos usos já realizados das informações que ele contém. Continua sempre possível colocar novas questões a um documento já explorado, com a esperança de se obter informações novas em resposta. A pesquisa científica não deixa de explorar esta via: que se pense, por exemplo, nos benefícios que a demografia histórica recentemente obteve de uma nova interrogação dos registros paroquiais (MEYRIAT, 2016, 243).

A formação do usuário para colocar novas questões a um documento exige, pois, uma disposição política e institucional para responder de modo intencional, sistemático e formal a este desafio, que a contemporaneidade nos coloca. Não são iniciativas espontâneas, por mais organizadas e imbuídas de boa vontade, que vão responder de modo satisfatório a uma necessidade nacional e global, que apresenta consequências cruciais para os campos da ciência, da economia, da política, da cultura e da sociedade. Principalmente no Brasil, onde a escola ainda é a agência principal, e em muitos casos única, de acesso da maioria dos filhos e das filhas das classes populares ao conhecimento sistematizado.

Quando estudamos a história do desenvolvimento do conceito de competência em informação (information literacy), a partir dos estudos de Dudziak (2016) nos damos conta da iniciativa de pesquisadores atuando em instituições que prestam serviços de informação, mas que vão adquirindo, necessariamente, contornos institucionais e políticos imprescindíveis para sua consolidação e desenvolvimento, seja unindo a biblioteca à escola, seja na proposição e efetivação de desenhos curriculares, seja na elaboração documental de critérios e normas que orientem, avaliem e subsidiemessa formação, sendo, nos Estados Unidos, a American Library Association (ALA), a principal referência desse processo.

\section{DOCUMENTAÇÃO, COMPETÊNCIA EM INFORMAÇÃO E PEDAGOGIAS PARA A FORMAÇÃO DO USUÁRIO}

Para atuar de modo eficiente na cadeia documentária, que é a "coleta de documentos, extração de dados e de informações, classificação, armazenamento e recuperação desses dados, difusão e resposta às questões" (MEYRIAT, 2016, p.247), o usuário necessita uma mínima competência em informação.

E esta competência requer uma aprendizagem ao longo da vida e uma abordagem pedagógica que favoreça intencionalmente a autonomia e a busca pelo conhecimento, através da pesquisa como princípio educativo, da participação, do espírito crítico e solidário, ao entender que a aprendizagem colaborativa, em pequenos grupos, apresenta maior 
potencialidade, enriquecendo a qualidade do processo formativo e informativo, compartilhando informações e interpretações tendo maior probabilidade de gerar um ciclo virtuoso, num ambiente acadêmico acolhedor, que favoreça a produção de conhecimento e da aprendizagem.

AUNESCO, incorporando contribuições de propostas anteriores, propôs a ampliação do conceito de competência em informação, na intenção de obter uma noção unificada, denominada Media and Information Literacy (WILSON, 2013), que se expressa por meio de:

1. A competência em informação - mobilização de conhecimentos, habilidades e atitudes relacionadas com o universo informacional, capacidade de leitura e escrita, busca e uso da informação, organização e manipulação de dados para a produção de novas informações e conhecimentos, sua disseminação e preservação visando o seu reuso futuro;

2. A competência mediática - convergência de conhecimentos, habilidades e atitudes em relação ao uso e compreensão dos meios e processos de comunicação de massa, que ocorrem em estados avançados de desenvolvimento da sociedade.

O conceito de competência em informação pode ser analisado em três aspectos que estão indissoluvelmente intricados: o teórico (conhecimento - saber), o técnico (habilidades - saber fazer) e o prático (atitude - fazer).

Na perspectiva de fazer o documento, conforme concebeu Meyriat (2016), o aspecto atitudinal apresenta sua relevância, pois a dimensão autoral e criativa do sujeito em relação ao universo informacional ocorre no processo de um fazer, que se constitui num exercício de poder, no qual o técnico, o humano e o político se fundem num mesmo ato ou numa sequência de atos e seus desdobramentos.

Seria ingênuodeixar de reconhecer que a criatividade e a autoria também estão presentes na elaboração do construto teórico e na confecção da metodologia. Contudo, observamos que não basta saber e saber fazer, é preciso, portanto, fazer, para o que o saber e o saber fazer adquiram o significado ético-político na materialidade constituinte que dá sentido a todo processo que a relação teoria e prática requerem. A capacidade de leitura e escrita, a busca e o uso da informação, a manipulação de dados para a produção de novas informações e conhecimentos, só adquirem significado pleno quando ocorre sua disseminação e preservação, visando futuras reutilizações. 
Se acreditarmos, segundo Henriette Gomes (2019) ${ }^{1}$, que informação é conhecimento em estado de compartilhamento, os dados organizados e interpretados teórica e sistematicamentesó se transformam em informação que constituirão documentos se forem tornados públicos. A recente divulgação do desmatamento da Amazônia pelo Instituto Nacional de Pesquisas Espaciais (INPE), por exemplo,gerou uma politização deste setor diante da reação do atual presidente brasileiro, contrário à divulgação, argumentando que a publicização de dados ambientais dificulta relações comerciais.Revelada tal contrariedade, exigiu que antes de que tais informações fossemdivulgadas, devem passar pelo seu controle direto, o que provocou protestos, manifestos de apoio ao INPE por grupos de cientistas, e toda uma reação contra a atitude autoritária do atual presidente do Brasil.

Este acontecimento reforça que o aspecto atitudinal da competência em informação implica autoria, criatividade, sabedoria para ler o contexto político, social e cultural no qual a ciência produz seu conhecimento. Exige ética para basilar nossas atitudes no respeito, no cuidadoteórico e no rigor metodológico e técnico com o nosso trabalho e também no cuidado e na atenção com o outro,além de coragem para se posicionar diante da realidade sobre a qual se age, ao disseminar a informação que a sociedade precisa saber para orientar suas próprias ações.

Por outro lado, a produção científica nesta área assinala a universalidade do paradigma de desenvolvimento de competências em informação para o século XXI e a necessidade da sua inclusão nos conteúdos dos diferentes níveis de educação ao longo da vida (ALVES, ALCARÁ, 2014). Reconhecemos sua importância para nossa reflexão-ação, mas também nos preocupamos com seus reducionismos políticos e epistemológicos que podem reduzir ou manter sob um controle ideológico rígido o usuário em sua busca pela informação em função de suas necessidades e interesses.

Nesse sentido, uma pedagogia que não contemple o aspecto crítico da formação humana para a competência em informação, pode priorizar o aspecto técnico e teórico em detrimento desta importante dimensão, na qual o fazer adquire relevância política para o sentido emancipatório que a informação contém, tornando o documento que suporta esta informação, um objeto de disputa política no seio de uma sociedade cindida.

Por isso, devemos tomar cuidado e refletir profundamente sobre as pedagogias do aprender a aprender (Newton Duarte, 2003), que privilegiam demasiadamente o estudante como

\footnotetext{
${ }^{1}$ Conceito defendido pela autora em sala de aula, no semestre 2019.1, na disciplina Fundamentos Históricos e Epistemológicos da Ciência da Informação.
} 
centro do processo educativo, mas que se constituem em pedagogias liberais, que privilegiam a competitividade na luta pela inclusão individual num mundo de exclusão coletiva. Comentando uma passagem do livro do autor português Vitor da Fonseca, Newton Duarte (2003) afirma o seguinte sobre o "aprender a aprender":

\begin{abstract}
O autor não deixa qualquer dúvida nessa passagem quanto ao fato do "aprender a aprender" ser apresentado como uma arma na competição por postos de trabalho, na luta contra o desemprego. O "aprender a aprender" aparece assim na sua forma mais crua, mostrando seu verdadeiro núcleo fundamental: trata-se de um lema que sintetiza uma concepção educacional voltada para a formação, nos indivíduos, da disposição de uma constante e infatigável adaptação à sociedade regida pelo capital (DUARTE, 2003, p.11).
\end{abstract}

Muito embora a proposta pedagógica dos autores Fonseca e Perrenoud, analisados por Duarte (2003), valorize a autonomia e as potencialidades cognitivas dos indivíduos, no aspecto político a valorização se encontra na adaptação passiva aos ditames da realidade de um capitalismo cada vez mais excludente e reduz a autonomia tão valorizada e as potencialidades individuais a vantagens competitivas na luta em ser incluído nesta sociedade tão desigual.

A suposta qualidade formal não encontra respaldo na qualidade política desta proposta pedagógica do "aprender a aprender".

\begin{abstract}
Somente a compreensão mais profunda do conceito permite a necessária transição da racionalidade instrumental para a racionalidade substantiva que não ignora o que é valorizado em uma nação. [...] A exemplo do que ocorreu nos Estados Unidos, o desafio consiste em buscar a institucionalização da competência em informação em âmbito nacional, tomando por base nossa história. Compreender como se deu o desenvolvimento do país, do sistema educacional e de trabalho, levando em conta as necessidades sociais e econômicas das populações locais e sua diversidade, assim como conhecer os meandros políticos são pontos essenciais que não prescindem da necessária mobilização de bibliotecários, educadores e gestores (DUDZIAK, 2016, p.46).
\end{abstract}

Percebemos que esta proposta pedagógica vem de encontro ao que a competência em informação defendeu ao longo de seu desenvolvimento, pautado numa cidadania e no acesso livre à informação em contextos de liberdades democráticas e de expansão dos serviços especializados de informação. Tal abordagem também restringe a cadeia documentária a um tecnicismo empobrecedor, que reduz a função informativa do documento a um horizonte político de adaptação ao que está dado, não ao que pode ser transformado. 
Portanto, Meyriat (2016) aponta para o papel ativo do receptor (usuário) na produção de um documento, a partir do significado dado por este às informações deste documento, caracterizando-o numa abordagem interativa, na qual, tanto o usuário, quanto o documento e as ferramentas, instrumentos e instituições, ou seja, todo o sistema técnico-social da documentação está em constante processo de ressignificação e mudança.

Este profícuo processo requer uma competência em informação do usuário para atuar de modo coerente e produtivo, mas que deve estar atenta às propostas pedagógicas que dela decorrem, pois, ao invés dessas pedagogias fomentarem a interação, a participação ativa e crítica do usuário que busca informação para responder a perguntas para suas diversas demandas, podem promover a adaptação tecnicista à realidade política, em detrimento da transformação social.

\section{FOSKETT E A COMPETÊNCIA EM INFORMAÇÃO}

Ao tomar conhecimento, mesmo que de modo breve, de parte da produção intelectual de Douglas John Foskett, fomos percebendo seu interesse pelo que Meyriat denominou de sistema de produção e distribuição do objeto, que poderá se tornar um documento “[...] como o produto de uma vontade, aquela de informar ou se informar - a segunda ao menos sendo sempre necessária” (MEYRIAT, 2016, p.243).

Como veremos mais abaixo, Foskett (1973) também apresenta ideias que podem ir ao encontro dessa posição conceitual-empírica de Meyriat, na medida em que acena para o papel do usuário na dinâmica do sistema técnico-social, o que nos leva à associação com o conceito de competência em informação proposto pela ALA e desenvolvido pela UNESCO e outros autores e instituições, conceito central do nosso projeto de doutoramento em desenvolvimento no Instituto de Ciências da Informação da Universidade Federal da Bahia.

Foskett (1973) nos apresenta brevemente um panorama das origens e do desenvolvimento dos sistemas formais de comunicação do conhecimento, desde o livro publicado por Aristóteles até a revolução cibernética, que caracteriza nossa contemporaneidade. Neste desenvolvimento, ele nos aponta alguns problemas entre os quais, a colaboração entre os "homens sábios" e os homens de negócio, com o objetivo de difundir informações no mercado. Referidos problemas podem causar: 
- A homogeneização dos temas e problemas que as publicações científicas apresentam sob um paradigma dominante;

- A concepção dos sistemas de bibliotecas e documentos como fins em si mesmos, alienados do sistema político, social, econômico e cultural mais amplo que o influencia decisivamente;

- A limitação do trabalho dos profissionais da Ciência da Informação, bibliotecários, documentalistas, museólogos etc., a alimentar computadores e sistemas na era cibernética;

- A busca de determinação do usuário como consumidor de mercadorias de informação, a partir de propagandas que visam gerar necessidades artificiais de informação e conhecimento, descaracterizando assim a própria origem e dinâmica do documento;

- A proliferação de novos periódicos, que Foskett (1973) denominou de "supercomercialização do produto "informação" que, ao invés de representar um salutar crescimento no mundo do saber, gera efeitos nocivos, tais como: a) a queda de nível dos trabalhos científicos publicados; b) a duplicação (o mesmo artigo publicado em mais de um periódico, livro); c) a publicação em excesso de "notícias" de pouco interesse ou mesmo duplicadas; d) a proliferação de notas banais e encomenda a autores de renome, mas que pouco têm a acrescentar ao conhecimento em função de não terem, no momento, nenhuma síntese nova de interesse para a pesquisa.

Em decorrência de suas observações, o autor pergunta: "Devem os padrões de publicação ser ditados pelo mercado ou pela avaliação de especialistas autorizados?" (FOSKETT, 1973, p.9). E faz a crítica ao mercado como regulador principal da atividade de produção e difusão da informação científica:

[...] mas, como acontece com toda a produção de mercadorias, existe atualmente uma tendência óbvia de depender mais da capacidade do mercado do que da satisfação de uma necessidade real ou da qualidade do produto (FOSKETT, 1973, p.10).

Preocupado com a transformação da informação em mercadoria, determinada pelos princípios de mercado capitalista, ele não oferece resposta pronta, mas sugere o caminho alternativo da esperança por profissionais comprometidos com a qualidade de todo sistema 
técnico-social da informação. "Resta, portanto, muito a ser dito em favor da opinião de que toda a edição de periódicos especializados deve estar nas mãos de sociedades científicas e profissionais ou de universidades" (FOSKETT, 1973, p.10). Como vimos mais acima a própria divulgação da informação por instituições competentes para tal está em jogo no campo político brasileiro, neste caso, depende muito mais da satisfação de um governante, ou de um grupo político, do que da real necessidade e da qualidade da informação, expressando como fenômenos políticos e sociológicos do nosso contexto também interferem na cadeia documentária de um campo de conhecimento.

Ao longo de sua reflexão sistematizada em torno dos aspectos sociológicos dos sistemas formais de informação e comunicação do conhecimento, Foskett (1973) vai oferecendo pistas de como a competência em informação vai se fazendo necessária e indica o contexto de surgimento da necessidade desta competência quando afirma que:

\begin{abstract}
A terceira grande mudança intelectual e industrial, às vezes chamada de Revolução Cibernética, intensificou todos os problemas dos métodos de comunicação formal. Muitos fatores têm contribuído para esta crise: o grande aumento do número de pesquisadores, que naturalmente desejam publicar seus trabalhos; o consequente aumento da indústria editorial; as espetaculares mudanças ocorridas nos transportes, o que significa que um número maior de oportunidade de os sábios se encontrarem e trocarem ideias; o consequente incremento do ritmo de pesquisa e de sua extensão à prática. Nenhum desses fatores naturalmente é novo, mas o volume de seu crescimento tem levado a uma posição radicalmente nova, em que os antigos caminhos que durante muito tempo foram satisfatórios têm sido submetidos a uma exame minucioso, novo e intensivo. (FOSKETT, 1973, p.5-6)?
\end{abstract}

Neste contexto de explosão do número de publicações e da produção quase infinita de informações, é preciso ser capaz de reconhecer quando a informação é necessária, ter capacidade de localizá-la, seja através de iniciativa própria seja através dos documentalistas e bibliotecários, que fazem a mediação entre o usuário, a documentação e a informação desejada, a fim de a avaliar e a usar de forma eficaz.

Foskett vai ao encontro da perspectiva de documento de Meyriat, quando reflete criticamente sobre a concepção do sistema de informação como um fim em si mesmo. Entendemos com estes autores, que qualquer sistema está inserido em sistemas mais amplos, cuja existência se dá em função do usuário que busca a informação, e não seu contrário. Ou seja: a dinâmica do sistema de informação, pelo menos numa democracia, é aberta em espiral, na qual o atendimento à necessidade do usuário, que nunca pode ser cristalizado num tipo único e homogêneo, é determinado pelas estruturas sociais, políticas e culturais de sua época, tendo 
ele mesmo uma incessante singularidade, constituída na dinâmica das interações socioculturais, num palco social e cultural objetivo de negociação de sentidos e de subjetividades.

As capacidades cognitivas do usuário de saber quando a informação é necessária, de localizar esta informação, avaliar sua pertinência e usá-la de modo eficaz e eticamente são apontadas por Foskett a partir das contribuições do psicólogo suíço Jean Piaget. Este pesquisador busca compreender e explicar como a mente humana opera uma informação nova em suas estruturas mentais, pelos processos de assimilação e acomodação, através da ação do

sujeito. É justamente na ação do sujeito, em suas necessidades de informação, exercendo sua cognoscibilidade como caminho dialético entre a compreensão e transformação do mundo, enquanto transforma a si mesmo nesse processo, que todo sistema técnico-social da informação é transformado.

Portanto, tanto Foskett, quanto Meyriat e Dudziak se contrapõem a propostas pedagógicas de veio reducionistade formação do usuário quando fazem a crítica à transformação da informação em mercadoria, controlando e homogeneizando as necessidades e interesses dos usuários em relação à informação; na perspectiva de uma atividade documentária na qual o usuário tem papel destacado, num processo ativo, interativo e dinâmico, "fazendo documentos" com sua curiosidade criativa e; numa competência em informação que ultrapasse a concepção pedagógica de formação do usuário da informação da proposta do “aprender a aprender" para uma abordagem crítica, comprometida com a compreensão e transformação da sociedade numa perspectiva democrática, emancipatória e solidária.

\section{CONCLUSÃO}

Na perspectiva interativa de documento e documentação de Jean Meyriat (2016) a competência em informação potencializa o usuário e a própria dinâmica do sistema técnicosocial da documentação, uma das características da atividade documentária, pois se um elemento do sistema sofre uma transformação, todos os demais também serão ressignificados, principalmente quando esse elemento é o usuário.

As contribuições de Meyriat, Foskett e Dudziak nos ajudam a entender e aprofundar a relação entre informação e formação, tendo a competência em informação como conceito 
central para compreender o usuário que ativa, que faz o documento, mobilizando seus conhecimentos, habilidades e atitudes associadas ao campo informacional, ao perguntar pela informação necessária para resolver um problema, utilizando suas capacidades de leitura e de escrita, de busca e uso da informação, da organização e manipulação de dados para a produção de novas informações e conhecimentos, sua publicização e preservação, na atividade documentária que encontra nas necessidades de informação do usuário sua finalidade maior.

As pedagogias do aprender a aprender embora tentem responder às necessidades de formação desse usuário, na perspectiva do desenvolvimento de sua competência em informação, exploram sua dimensão técnica e individualista em detrimento da imprescindível dimensão política e humana, o que contraria o ímpeto democrático de toda a história do desenvolvimento conceitual da competência em informação e da própria concepção de documento apresentada por Meyriat, o que nos incita a pesquisar outras propostas pedagógicas que sejam coerentes com as propostas de democratização cada vez maior e mais ampla da informação e do seu acesso por usuários cada vez mais competentes para lidar com a informação.

\section{REFERÊNCIAS}

ALVES, F. M. M.; ALCARÁ, A. R. Modelos e experiências de competência em informação em contexto universitário.Encontros Bibli: revista eletrônica de biblioteconomia e ciência da informação, Florianópolis, v. 19, n. 41, p. 83-104, dez. 2014. Disponível em $<$ https://periodicos.ufsc.br/index.php/eb/article/view/1518-2924.2014v19n41p83/28291>. Acesso em 23 jul. DOI: 10.5007/1518-2924.2014v19n41p83.

\section{AMERICAN LIBRARY ASSOCIATION. Presidential Committee on Information}

Literacy: final $\quad$ report. Washington, 1989. Disponível
em $<$ http://www.ala.org/acrl/publications/whitepapers/presidential $>$. Acesso em 23 jul. 2019.

DUARTE, N. Sociedade do conhecimento ou sociedade das ilusões?: quatro ensaios críticodialéticos em filosofia da educação. Campinas, SP: Autores Associados, 2003.

DUDZIAK, E. A. Políticas de competência em informação: leitura sobre os primóridios e a visão dos pioneiros da information literacy. In: ALVES, F. M. M.; CORRÊA, E. C. D.; LUCAS, E. R. de O. (orgs.). Competência em informação: políticas públicas, teoria e prática. Salvador: EDUFBA, 2016.

FOSKETT, D. J. Alguns aspectos sociológicos dos sistemas formais de comunicação do conhecimento. Conferência pronunciada, sob os auspícios da Universidade de Brasília, Instituto Nacional do Livro, em Brasília, no dia 6 de março de 1971. Tradução de Antônio Agenor Briquet de Lemos. Revista de Biblioteconomia de Brasíliav. 1, n. 1, p. 3-14.1,jan./jun. 
1973.

$<$ http://www.brapci.inf.br/_repositorio/2010/03/pdf_915e1b3236_0008350.pdf $>$. Acesso em 23 jul. 2019.

MEYRIAT, J. Documento, documentação, documentologia. Perspectivas em Ciência da Informação, v.21, n.3, p.240-253, jul./set. 2016. C. M. A. Silva; M. de Britto; Cristina D. O. (trads.). Traduzido de: MEYRIAT, J. Document, documentation, documentologie. Schéma et Schématisation, n. 14, p. 51-63, 1981. Disponível em

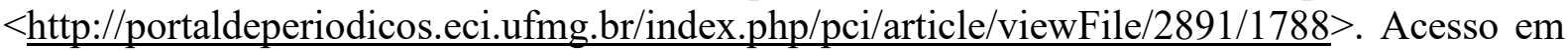
23 jul. 2019.

WILSON, C.Alfabetização midiática e informacional: currículo para formação de professores. $\quad$ Paris: UNESCO, 2013. $\quad$ Disponível $\quad$ em $<$ https://unesdoc.unesco.org/ark:/48223/pf0000220418 por $>$. Acesso em 23 jul. 2019. 